\title{
LITERACY STUDY OF TCFL TEACHER COMPETENCIES
}

\section{对外汉语教师应具备的素养研究综述}

\author{
Sofi Zhang \\ Chinese Department, Faculty of Humanities, BINUS University \\ Jl. Kemanggisan Ilir III no.45, Kemanggisan - Palmerah, Jakarta Barat 11480 \\ sofizhang@gmail.com
}

\begin{abstract}
TCFL teachers' competencies are a new and popular field of research in the Chinese language. These competencies will relate to the knowledge and skills that TCFL teachers should have, such as the knowledge in linguistics and Chinese linguistics, theory of the second language, learning strategies and teaching methodologies. Beside that, teacher should have a good awareness, psychological and emotional control. This article summarizes the results of literacy study of TCFL teachers' competencies. At first, these seem difficult to achieve, but by consistently accumulating teachers' knowledge and skills, its can help to give new TCFL teachers a clearer understanding of their role in education and help them make preparations. Accumulating knowledge and skills, controlling the role of psychology and emotions are very important that TCFL teachers must have as their lifestyle.
\end{abstract}

Keywords: Chinese language, teacher, competencies, literacy study

\section{内容摘要}

目前世界各国越来越重视汉语, 汉语教师的需求也越来越高。论对外汉语教师应 该具备哪些素养, 就会涉及到教师的知识与能力素养, 情感素养, 心理素养。虽然总 结出以后的结果使想作为一名对外汉语教师这个职业显得很难做到, 但通过这些研究 结果, 可以帮助新的教师对对外汉语职业有更清楚地了解并且做些准备。教师的知 识, 能力, 情感, 心里都是需要不断的积累和培养出来的, 也可能是教师终身要做的 事。

关键词：对外汉语教师, 知识与能力素养, 情感素养, 心理素养。 


\section{前言}

新中国的对外汉语教学始于 20 世纪 50 年代初, 而汉语教师培训工作发端于 20 世 纪 60 年代中期, 直到 80 年代后期, 才有专门针对对外汉语教师队伍建设的研究成果 问世。相对于对外汉语教学的语言本体研究或教学法研究而言, 对外汉语教师队伍建 设的研究起步较晚, 成果也不是很多。

21 世纪, 世界各国 “汉语热” 这个现象到目前还是很明显, 尤其是过了在北京的 奥运会, 想来中国旅游, 学习中国话和中国文化, 甚至来中国搞生意、找工作的人也 愈来愈多。这样, 汉语教师的需求就越来越多了, 不仅在中国国内很需要, 而且在世 界各国也很缺少汉语教师。

\section{一、 教师应该具备的知识和能力}

教师也是教学中成败最关键的要素。为了提高汉语作为外语教学的水平, 加强对 外汉语师资队伍的建设, 促进对外汉语教学事业发展, 教育部于 2004 年 10 月出台了 《汉语作为外语教学能力认定办法》, 明确了对从事汉语作为外语教学工作的中国公 民和外国公民所具备的相应专业知识水平和技能认定的办法。具体而言, 就是要求对 外汉语教师应该具备语言本体知识（语言学、汉语言文字学、外语、中西文化、教育 学和心理学) 以及语言表达和创造能力, 现代教育技术应用合作精神, 科研和亲和能 力等（郝晓梅, 2005）。

郝晓梅（2005）认为对外汉语教师应该具备的知识是语言学知识, 汉语语言知识 (语音, 语调, 汉子, 语法, 词汇) , 外语知识, 中国文化知识, 教育学和心理学的 知识, 而应该具备的能力是课堂组织能力, 创造能力, 掌握现代教育技术和有效利用 多媒体教学的能力。

邓恩明 (2005) 认为, 在对外汉语教师的知识结构中, 应当包括汉语理论知识、语 言教学法理论知识、语言学知识和心理学知识, 以及文学、文化知识。对外汉语教师的 能力结构体现在教学方面则应包括观察能力、分析辨别能力、思维判断能力、想象创 新能力、口头表达能力, 以及组织能力、交际能力和应变能力。

张德金金（2001）从教学基本功的角度论述了对外汉语教师应具备的知识与能力。 他认为, 精通汉语是对外汉语教师的 “内功” ; 解乃至熟悉第二语言教学理论与教学 法流派, 至少掌握一门外语, 具有文化修养并至少熟悉那门外语的所属文化, 拥有一定的 电脑技能, 是对外汉语教师的 “外功” 。只有练就过硬的基本功, 才能当一名合格的、 称职的乃至出色的对外汉语教师。

黄晓颖 (2004) 认为, 备课是决定课堂教学质量高低的关键。要使一节课富有艺术 感染力、达到最佳教学效果, 教师首先必须讲究备课的艺术。因此, 对对外汉语教师素 质的要求应当包括具备驾驭备课艺术的能力。 
姜丽萍 (2008) 总结, 教师首先要对学科的基础知识有广泛而准确的理解, 熟练 掌握相关的技能、技巧。只有对知识和技能有了准确的熟练掌握, 才有可能花更多的 精力去设计教学, 才能在课堂上关注学生的进展情况, 而不是把注意力集中到 “自己 不要把知识讲错” 的担心上。具体来说, 教师要通晓所教的专业知识 (现代汉语知 识、语言学知识、文化知识、外语知识), 具有扎实的教学理论知识, 要加工和驾驭 教学内容的能力, 要胜任多种教学工作的能力, 协调人际关系的能力, 对教学的控制 能力, 运用现代技术的能力, 研究能力。

从以上可以总结, 对外汉语教学内容就围绕着现代汉语知识、中国历史和文化知 识, 而为了能组织好课堂教学, 对外汉语教师应该具有语言学知识、外语知识、教学 理论知识、心理学知识。然后在这些的知识上加强并且磨练自己在加工和驾驭教学内 容的能力、交际能力、课堂控制能力、备课艺术能力、现代技术能力。

知识可以通过读书、听课获得, 有可能在短期内增加, 也可能因遗忘而减少。而能 力是需要经过较长时间的学习、体会、训练而形成, 而一旦形成, 就轻易不会失去。一 个人有知识不一定有能力, 但学识浅薄必定造成能力的欠缺, 知识与能力二者相辅相 成, 既有联系又有区别。想成为一名深受学生欢迎的对外汉语教师, 不断完善自己的 知识和能力, 不断提高自己的素质, 要了解对外汉语这门学科的特点, 性质和教学规 律, 有意识地培养自己各方面的能力, 只有这样才能提高对外汉语教学水平。

\section{二、 教师应该具备的意识}

对外汉语教师的基本素质研究也很关注对教师应具备的意识的论述。陆俭明 （2005）指出对外汉语教师应有的职业意识：对外汉语教师要树立很强的学科意识和 学习、研究意识, 还要树立自尊自重的意识。我们的教师应当明确, “对外汉语教学的 基础教学是汉语言文字教学, 其他学科的教学从整体上来说都是为汉语言文字教学服务 的”, 对外汉语教学又不仅仅是汉语言文字教学, 它 “必须走以汉语教学为基础的、开 放性的兼容整合之路”。

市觉非（1997）把对外汉语教学放在新世纪世界政治、经济、文化的大背景下进 行讨论, 指出 21 世纪的对外汉语教师应当具备的时代意识。除了师德、知识、外语水 平、教学艺术外, 市觉非还特别强调了教师应具有较高的使用电脑的能力。对外汉语教 师只有具备了学科意识, 才能明了自己的职责和所求。

李泉 (2005) 则对对外汉语教师的课堂教学意识作了较全面的论述, 提出了教师在 课堂教学中应当有学生意识、交际意识、语言意识、课型意识、目的意识等。李泉认 为, 强化这些意识将有助课堂教学效率的提高。

黄宏 (2002) 认为, 培养派遣到国外任教教师的跨文化交际意识, 培养他们应对在 国外工作时的文化冲突从而预防文化休克的能力, 是出国师资培训工作的当务之急。周 健 (2004) 则指出, 对外汉语教师应当有双语、双文化的意识和自觉, 不仅要对汉语文 
化有深刻的认识, 同时对于学生的母语文化也有相当深入的了解, 从而能自觉地将文化 比较运用于对外汉语教学。

张和生 (2006) 认为, 无论是时代意识、课堂教学意识, 还是跨文化交际意识, 都可 以并入对外汉语教师的职业意识。所谓职业意识, 就是一种观念, 它反映出从业者对自 己职业的认识水平。

实际上, 教师只要对自身职业有了正确的认识, 就会有自觉提高自我职业素养的 动力, 就会做主动完善自我的有心人。这可能就是对外汉语教师最基础的要求。

\section{三、 心理素养}

从教师的的职业角色，可以了解教师应该具备哪些心理素养。每个教师都在不同 的层次、不同的侧面的学校社会生活中, 扮演不同的社会角色。邵瑞珍 (1990) 对教 师的角色进行分析：第一、权威者的角色, 指知识的传授者、团体的领导者、模范公 民、纪律的执行者、家长的代言者; 第二、心理工作者的角色, 指朋友与知已、人际 关系艺术家、心理治疗者。

徐子亮 (2007) 把对外汉语教师的职业角色分成四个。一、学习的示范者, 对外 汉语教学与外语教学一样, 教师教的目的语 (汉语) 应该规范的, 语音语调要准, 语 法用词也要用得妥当, 因为学生在学习中, 会自觉地、有意地或不直觉地、无意地加 以模仿。二、学习的指导者, 现代意义上教师不仅是传授知识, 他还必须在学生知识 学习和技能掌握的过程中加以指导, 帮助学生建构知识体系, 促进学生能力的培养。 三、教学的组织者, 组织教学活动包括课堂活动和课外实践, 实现教学活动目标, 是 教师最基本的工作。四、教学的研究者, 教师不仅从事教学活动, 还应对教学活动以 及教学活动的对象一一学生加以研究。教师必须具备探求、研究的意识和精神, 不断 发现问题、进行思考、努力解决问题, 提高学习效率, 了解学生的心理共性, 掌握学 生的个性差异，以便因人而异，因材施教。

姜丽萍 (2008) 解释对外汉语教师应具备的心理素养, 教师要始终保持一种健康 的心态, 要有良好的性格和坚强的意志, 要善于调节情绪。积极、乐观、敬业, 在教 学中发自内心地爱学生、爱教学、爱工作, 能从教学中体会到美感、愉悦感、成功感 与崇高感, 把教师的职业道德要求升华到完善自我品格、超脱情操的精神层面上来就 是所谓的健康心态。意志品德主要表现在坚定、果断、沉着、冷静、耐心, 自信和自 控。能克服并调节在教学过程中或者生活中的压力。

从事教育工作以后, 教师只要意识到自己的职业角色, 知道什么时候应该扮演着 学生的朋友, 什么时候要扮演着指导者, 还是在课堂上时扮演着组织者/领导者的时 候, 就已经胜任教学工作的一部分心理问题。 


\section{四、情感素养}

徐子亮（2007）归纳对外汉语情感素质, 学生对教师的信赖, 往往来自教师的高 度责任感; 学生对学习的信心, 往往来自教师稳定的情绪; 学生对学习的热情, 往往 来自教师丰富的学识与广泛的兴趣。因此对外汉语教师具备这些人格特征, 是教学取 得良好成效的重要因素。

责任感是个人自觉地把自己所承担的任务和负责的工作做好的一种心情, 是一个 教师所必备的基本素质。

稳定的情绪表现在教师对学生的耐心以及对自身焦虑的控制。语言学习是一项需 要意志和毅力的学习。学生在学习过程中会遇到各种困难和问题, 需要教师反复加以 说明, 耐心地用各种方法帮助学生理解和掌握。教师稳定地情绪是教学工作顺利开展 并取得良好效果的基本保证。

对外汉语教师广泛的兴趣表现在对新知识的追求、对事物的探索, 对所教的学科 可有效的教学倾注极大的兴趣; 表现在善于思考和探索, 善于进行各项交际活动; 也 表现在对生活经验和世界知识的热情关注和吸取。教师的兴趣也会引起学生的兴趣。

姜丽萍（2008）认为, 教师对学生的真诚的爱, 既是教师良好心理素质的一种表 现, 也是一种重要的教育力量。移情, 也就是能站在别人的立场上, 设身处地为别人 着想, 教师在教学中要善于对教材、对学生、对所教课程移情。非权势, 教师在与学 生交往中要有民主平等的意思, 尊重课堂内每个人, 建立一种和谐、融洽的师生关 系。最大限度的宽容, 宽容也是一种心理品质, 使对待他人的利益、信念、信仰、行 为习惯的一种友善态度。教学过程中不可避免师生产生一些小摩擦, 教师要学会最大 限度的矿容, 不断锤炼自己的性格, 让爱永驻心间。

教师的情感无路是积极或者消极的都会感染学生。积极的情感当然使师生关系融 洽, 使学生产生亲近教师的心理效应。但同样的情况, 教师消极的情感也会使学生没 有安全感, 害怕, 怀疑, 讨厌教师甚至讨戻老师所教的课。一旦学生对老师产生消极 情感, 就会影响教学中各个方面环节了, 老师就很难接近学生, 很难把知识传授给学 生。

\section{小结}

对外汉语教学的基本原则之一是 “以学生为中心, 以教师为主导” 。教师的教 学, 最主要的任务是给学生 “传道、授业、解惑”, 这就要求教师必须具备洲博的学 识、一定的专业知识和技能, 以及教学的组织能力。另外教师的对学生的真诚的爱、 高度责任感、良好的心理素质和广泛的兴趣, 也是吸引学生全新投入学习的重要条 件。 


\section{参考文献}

郝晓梅. (2005), 《对外汉语教师应具备的知识素养和能力》, 北京: 北京教育。

刘 珣. (1997), 《对外汉语教学概论》, 北京: 北京语言文化大学出版社。

张德金金. (2001), 《功夫在诗外一一谈谈对外汉语教师的 “外功”》, 北京: 海外华文教育。

黄晓颖. (2004), 《对外汉语教学的备课艺术》, 北京: 汉语学习, 第 3 期。

姜丽萍. (2008), 对外汉语教学专业教材系列《对外汉语教学论》, 北京: 北京语言大学出版。

陆俭明. (2005), 《汉语教员应有的意识》, 北京: 世界汉语教学。

市觉非. (1997), 《21 世纪: 时代对对外汉语老师的素质提出更高的要求》, 北京: 语言文字应 用（增刊）。

李 泉. (2005), 《对外汉语教学理论思考》, 北京: 教育科学出版社。

黄 宏. (2002), 《浅议对外汉语公派出国教师的跨文化交际问题及其对策》海外华文教育。

周 健. (2004), 《论汉语教学中的文化教学及教师的双文化意识》, 北京: 语言与翻译。

张和生. (2006), 《对外汉语教师素质与培训研究的回顾与展望》, 北京: 北京师范大学学报。

邵瑞珍. (1990), 《学与教的心理学》, 上海: 华东师范大学出版社。

徐子亮. (2007), 《对外汉语教学心理学》, 上海: 华东师范大学出版社。

张 蓓. (2008), 《试论现代对外汉语教师应具备的素质》, 陕西: 陕西教育, 高校版。 